\title{
Effect of early amniotomy on the outcome of spontaneous labour: a randomized controlled trial of pregnant women in Enugu, South-east Nigeria
}

\author{
Livinus N. Onah, ${ }^{1}$ Cyril C. Dim, ${ }^{2}$ Uchenna I. Nwagha, ${ }^{2}$ Benjamin C. Ozumba ${ }^{2}$
}

1. Departments of Obstetrics and Gynaecology, College of Medicine Enugu State

University of Science and Technology, Enugu Nigeria

2. Departments of Obstetrics and Gynaecology, College of Medicine University of Nigeria Enugu Campus, Nigeria

\begin{abstract}
Background: Early amniotomy is common in obstetric practice but, its effectiveness has not been proven.

Objectives: To determine the effects of early amniotomy on the duration of labour, and other maternal / neonatal outcomes of uncomplicated pregnancies in Enugu, South-east Nigeria.

Methods: A randomized controlled study of 214 consenting term pregnant women at the University of Nigeria Teaching Hospital Enugu, Nigeria. Intervention group received amniotomy early in active labour while the control group had their membranes conserved.

Results: Mean duration of labour for the amniotomy group (279.4 \pm 53.7 minutes) was significantly lower than that of con- trol group $(354.4 \pm 67.5$ minutes $),(\mathrm{t}=-8.988, \mathrm{p}<0.001)$. Three $(3.8 \%)$ women in amniotomy group needed oxytocin augmentation as against $21(19.6 \%)$ women in the control group $R R=0.14$, (CI 95\%: $0.04-0.46)$, NNT $=16$. The two groups did not vary with respect to cesarean section rate, newborn Apgar scores, and need for new born special care unit admission. Conclusion: Early amniotomy when compared to fetal membrane conservation reduced the duration of labour and need for oxytocin augmentation among term singleton pregnant women in Enugu, Nigeria. Its routine use in well selected cases may reduce prolonged labour and its complications.
\end{abstract}

Keywords: Early amniotomy, duration of labour, oxytocin augmentation, term pregnancy, caesarean section rate, EnuguNigeria.

DOI:http://dx.doi.org/10.4314/ahs.v15i4.7

Cite as: Onah LN, Dim CC, Nwagha UI, Ozumba BC. Effect of early amniotomy on the outcome of spontaneous labour: a randomized controlled trial of pregnant women in Enugu, South-east Nigeria. Afri Health Sci. 2015;15(4):1097-103. bttp://dx.doi.org/10.4314/abs. v15i4.7

\section{Introduction}

The aim of labour management is to deliver healthy babies to healthy mothers with minimum adverse effects $^{1}$. This objective is achieved by close monitoring of maternal and fetal conditions during labour with appropriate interventions when necessary. One of these interventions introduced in labour management without much evidence is early amniotomy ${ }^{2}$ which can be described as the elective rupture of fetal membranes early in active phase of labour. Labour is described

\footnotetext{
Corresponding author:

Cyril C. Dim,

Departments of Obstetrics and Gynaecology,

College of Medicine University of Nigeria

Enugu Campus, Nigeria

P.M.B. 01129, Enugu. 400001. Nigeria

Email: cyril.dim@unn.edu.ng

Tel: +2348033341960
}

as active phase when the cervical dilation is $4 \mathrm{~cm}$ and above $e^{3}$. Early amniotomy is one of the most commonly performed procedures in modern obstetric practice with the aim of enhancing the progress of labour and preventing dystocia in women in spontaneous labour ${ }^{4,5}$. However, the effectiveness of this intervention in augmenting labour has not been proven ${ }^{4}$, so it remains a subject for debate and further research.

Early amniotomy may be beneficial in the early identification of problems during labour and for early intervention. For instance, it allows for close monitoring of the liquor, placement of electrodes and intrauterine pressure catheter ${ }^{6}$. On the other hand, it may be associated with increased risks of fetal heart rate abnormalities, cord prolapse, pains with request for analgesia, caesarean section rate, and infection because of increased rate of vaginal examination ${ }^{7-9}$. Furthermore, as part of prevention of vertical transmission of maternal infections, the procedure has relative contraindi- 
cations in women living with HIV/AIDS ${ }^{3,10}$. It is also avoided in patients with high fetal presenting part, cord presentation, placenta praevia, transverse lie and vasa praevia ${ }^{11}$. Though, early amniotomy is a component of active management of labour proposed to reduce rate of caesarean section for dysfunctional labour ${ }^{7}$, its effect on the duration of labour has not been consistent. Some studies have shown significant reduction of labour duration but, no effect on other outcome measures $^{12,13}$, while few have shown no consistent effect of the intervention on labour duration and other outcome measures $^{4,14}$. A randomized trial of 128 women in IleIfe, South-western Nigeria ${ }^{13}$, showed that the duration of labour in women that had early amniotomy was significantly shorter than the non-amniotomy group. But, there was no difference in the caesarean section rates, oxytocin use, and other outcomes between the groups ${ }^{13}$. In view of the inconsistencies inherent in the findings of previous studies; there is need for further research in this subject area. Therefore, this study was aimed at determining the effects of early amniotomy on the duration of labour, and other maternal / neonatal outcomes of women with uncomplicated pregnancies in Enugu, South-east Nigeria.

\section{Methods}

This was a randomized controlled study of consenting pregnant women admitted in the labour ward of University of Nigeria Teaching Hospital (UNTH), Enugu, South-eastern Nigeria, from November 2012 to April

2013. All singleton term pregnant women in spontaneous active labour with intact fetal membranes were eligible for the study. Exclusion criteria included abnormal presentations, cervical dilation of $6 \mathrm{~cm}$ or more, previous caesarean section, cord presentation, and medical complications in pregnancy such as diabetes mellitus, preeclampsia, and HIV infection. The ethical committee of the hospital approved the study.

Participants' randomization into the intervention (amniotomy) or control (No-amniotomy) group was accomplished by an independent statistician using a computer generated random number sequence that were placed into consecutively numbered opaque, sealed envelopes. These envelopes were kept in a secure locker in the labour ward. The randomization flow chart is shown in Figure 1.

The sample size (n) for the study was 107 women per group; it was based on standard deviation of mean la- bour duration from a previous study ${ }^{13}$, assumed standardized effect size of 0.4 , power of $80 \%$ at $95 \%$ confidence level, and drop-out rate of $10 \%$.

To reduce the difficulties associated with counseling women in labour as well as late presentation, screening of pregnant women for the study was done at the antenatal clinic of the hospital and those that met the above eligibility criteria (except being in labour) were identified and counseled individually about the study. Each consenting woman was reminded of the symptoms of labour and encouraged to present to the labour ward early in labour. Also, she was issued an identifier which she submitted at the labour ward of the hospital when in labour. On presentation of the identifier, her eligibility was re-confirmed by a trained assistant (senior resident doctor) and a written consent obtained. Afterwards, a sequential study number was assigned to the woman then, a medical intern on duty retrieved the envelope bearing the participant's number, and the woman was allocated to the group concealed in the envelope. Thus the sample size per group represents only eligible women that arrived in labour ward before dilating beyond $5 \mathrm{~cm}$.

Women assigned to the intervention group received amniotomy at a cervical dilatation of $4-5 \mathrm{~cm}^{13}$. Before the procedure, each woman was allowed to empty her bladder and pre-amniotomy fetal heart rate assessed. Observing aseptic procedure, the perineum was cleaned with dilute chlorhexidine and digital vaginal examination carried out to assess cervical dilatation and other Bishop Score parameters. After that, amniotomy was performed with Kocher's forceps using the standard $\operatorname{method}^{3}$ followed by post-amniotomy fetal heart rate assessment.

Participants assigned to the control group had their fetal membranes conserved. For both groups, labour was monitored actively with partograph, using the standard protocol of the hospital thus: the fetal heart rate was monitored quarter hourly by intermittent auscultation, uterine contractions and maternal vital signs were assessed half hourly, while vaginal examination was done every 4 hours (and 2hourly for those on oxytocin augmentation). Appropriate standard obstetric interventions were used to manage abnormalities in labour. Oxytocin augmentation was commenced for every participant that had cervical dilatation of $2 \mathrm{~cm}$ or less in 4 hour (slow progress) and stable feto-maternal condition irrespective of her group. However, for the no-amniot- 
omy group with slow progress, amniotomy was done and oxytocin infusion started at the same time. The oxytocin augmentation followed a standard protocol; starting with $4 \mathrm{miu} / \mathrm{min}$ and increasing at interval of 30 minutes to achieve adequate uterine contraction pattern of 3-5 contractions in 10 minutes, each lasting 40-60 seconds ${ }^{7}$.

The primary outcome measure was the duration of labour in both arms of the study. The secondary outcome measures were all-cause cesarean section rate, need for oxytocin argumentation, Apgar scores, and need for New Born Special Care Unit (NBSCU) admission.

For the purpose of this study, duration of labour was defined as the time interval in minutes from a partici- pant's randomization to delivery of the baby.

Statistical package for social sciences (SPSS) version

15.0 for windows was used for data entry and analysis. Data analysis was by intention to treat. Associations were tested with chi square test (categorical data) and independent t-test (continuous data) at 95\% confidence level. A p-value of $<0.05$ was considered as statistically significant.

\section{Results}

A total of 214 women were enrolled for the study and randomized equally into intervention (amniotomy) group ( $\mathrm{n}=107)$ and control (no-amniotomy) group $(n=107)$. All participants completed the study and were analyzed (figure 1)

Figure 1: Flow chart of the Study

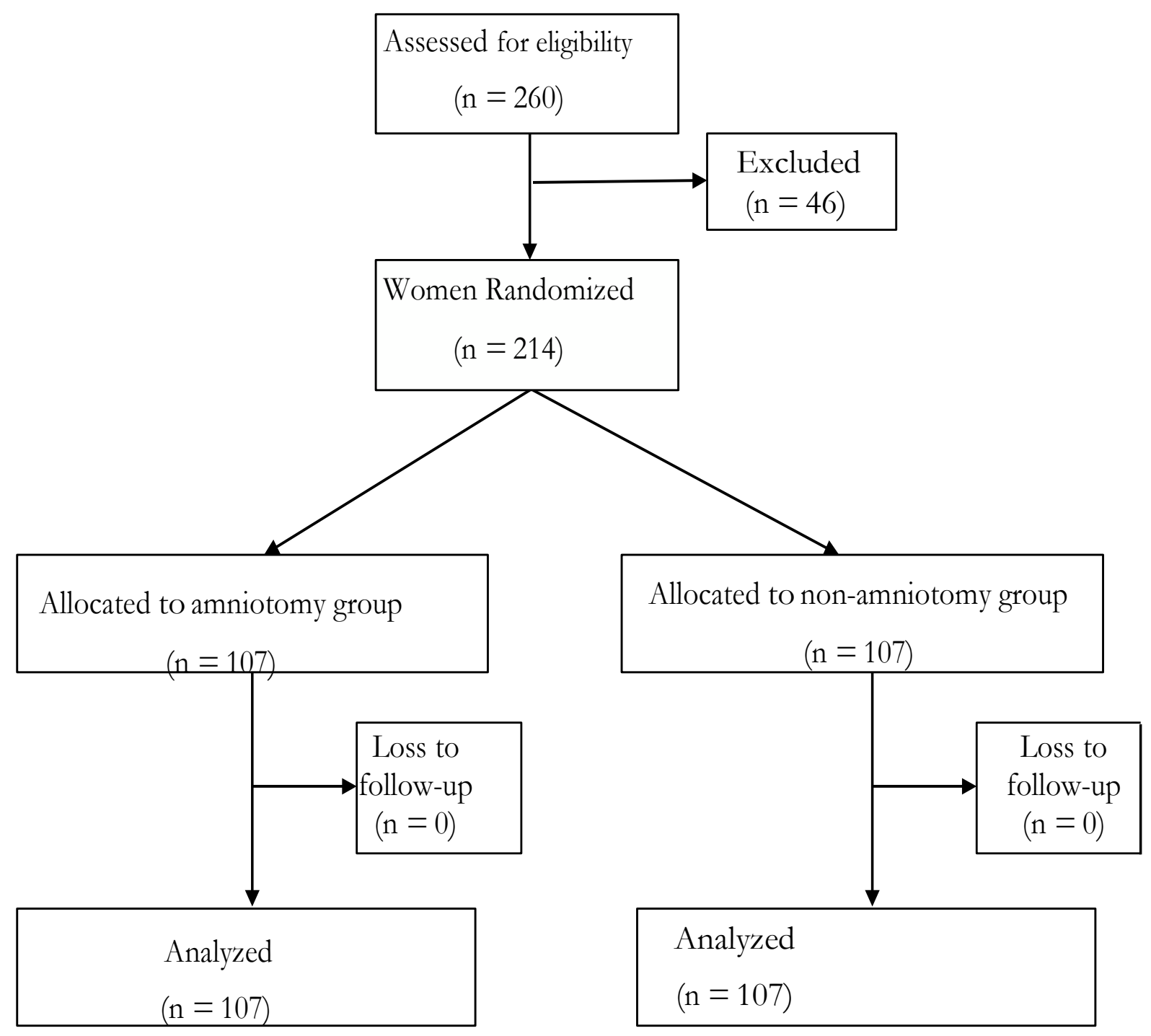


Participants' basic characteristics such as age groups, parity, gestational age, and neonatal birth weight were similar between the two groups (tables 1 and 2). For both intervention and control groups, majority of women were married $(86.0 \%, 92 / 107$ versus $82.2 \%$, $88 / 107)$, nulliparous $(32.7 \%, 35 / 107$ versus $35.5 \%$, $38 / 107)$, and aged $35-39$ years $(45.8 \%, 49 / 107$ versus 42.1, 45/107).

Table 1: Basic characteristics of participants

\begin{tabular}{lllll}
\hline Characteristics & Sub-group & $\begin{array}{l}\text { Amniotomy } \\
(\mathbf{n}=\mathbf{1 0 7})\end{array}$ & $\begin{array}{l}\text { Control } \\
(\mathbf{n}=\mathbf{1 0 7})\end{array}$ & \multirow{2}{*}{ P-value } \\
\cline { 2 - 4 } & & Freq (\%) & Freq (\%) & \\
\hline Age groups (years) & $20-24$ & $9(8.4)$ & $12(11.2)$ & \\
& $25-29$ & $18(16.8)$ & $22(20.6)$ & 0.765 \\
& $30-34$ & $9(8.4)$ & $11(10.3)$ & \\
& $35-39$ & $49(45.8)$ & $45(42.1)$ & \\
\hline Marital status & $40-44$ & $22(20.6)$ & $17915.9)$ & \\
& Single & $15(14.0)$ & $19(17.8)$ & \\
\hline Parity groups & Married & $92(86.0)$ & $88(82.2)$ & 0.56 \\
& Para 0 & $35(32.7)$ & $38(35.5)$ & \\
\hline 1 & $24(22.4)$ & $27(25.2)$ & $19(17.8)$ \\
& $2-4$ & $28(26.2)$ & $23(21.5)$ & \\
\hline
\end{tabular}

Table 2: Other basic characteristics of participants

\begin{tabular}{llll}
\hline \multirow{2}{*}{ unaracterıstıcs } & $\begin{array}{c}\text { Amniotomy } \\
(\mathrm{n}=107)\end{array}$ & $\begin{array}{l}\text { Control } \\
(\mathrm{n}=107)\end{array}$ & \multirow{2}{*}{$\mathbf{r - v a l u e}$} \\
\cline { 2 - 4 } & Mean \pm SD & Mean $\pm \mathrm{SD}$ & 0.67 \\
\hline Parity & $2.5 \pm 1.370$ & $2.5 \pm 1.383$ & 0.20 \\
\hline Gestational age (weeks) & $38.8 \pm 1.26$ & $39.1 \pm 1.38$ & 0.15 \\
\hline Cervical dilation at randomization $(\mathrm{cm})$ & $4.6 \pm 0.49$ & $4.7 \pm 0.46$ & 0.17 \\
\hline Birth weight $(\mathrm{kg})$ & $3.2 \pm .493$ & $3.1 \pm .418$ & \\
\hline
\end{tabular}

The mean cervical dilatation at randomization for the amniotomy group was $4.6 \pm 0.49$ median $=5$ (range 4 $-5) \mathrm{cm}$ while that of the control group was $4.7 \pm 0.46$ median $=5($ range $4-5) \mathrm{cm}$. The observed difference was not statistically significant $(t=-1.437, p=0.152)$. There was no maternal death or neonatal death in either group during the study period.

The mean duration of labour for the amniotomy group was $279.4 \pm 53.7$ minutes while that of the control was $354.4 \pm 67.5$ minutes. The observed difference (74.9 minutes) between the 2 groups was statistically significant $(t=-8.988, p<0.001)$. For nulliparous women, the duration of labour for the amniotomy and control groups were $287.1 \pm 66.54$ and $358.6 \pm 60.64$ respectively $(t=-4.785, \mathrm{p}<0.001)$, while the values for similar groups of parous women (para $\geq 1$ ) were $275.7 \pm 46.2$ and $352.0 \pm 71.3(\mathrm{t}=-7.507, \mathrm{p}<0.001)$. 
The over-all oxytocin augmentation rate for the study was $11.2 \%(24 / 214)$. Three $(3.8 \%)$ women in amniotomy group needed oxytocin augmentation as against 21 $(19.6 \%)$ women in the no-amniotomy group $\mathrm{RR}=0.14$, (CI 95\%: $0.04-0.46), \mathrm{p}<0.001, \mathrm{NNT}=16$

In all, the cesarean section rate among participants was $5.6 \%(12 / 214)$. The incidence of emergency cesarean section among women in the amniotomy group $(6.5 \%$, $7 / 107)$ did not differ from that of the control group $(4.7 \%, 5 / 107) \mathrm{RR}=1.4,(\mathrm{CI} 95 \%: 0.46-4.27), \mathrm{p}=$ 0.768 .
Thirteen (12.1\%) and $17(15.9 \%)$ babies had low 1st minute Apgar score $(<7)$ in the amniotomy and control groups respectively. The observed difference was not statistically significant $(p=0.431)$. Likewise, the proportion of babies with low 5th minute Apgar score did not differ between the two groups $(0.9 \%, 1 / 107$ versus $2.8 \%, 3 / 107, \mathrm{p}=0.62)$. Also, the proportion of neonates that needed New Born Special Care Unit (NBSCU) did not differ between the amniotomy and control groups $(p>0.05)$. Further details of the association between early amniotomy during labour and selected maternal / neonatal variables are shown in table 3 .

Table 3: Early Amniotomy verses Apgar Scores / Admissions to New-born special care unit

\begin{tabular}{llllll} 
Variable & Variable & $\begin{array}{l}\text { Amniotomy } \\
(\mathrm{n}=107)\end{array}$ & $\begin{array}{c}\text { Control } \\
(\mathrm{n}=107)\end{array}$ & P - value RR (Cl 95\%) \\
\cline { 3 - 4 } & category & Freq (\%) & Freq (\%) & & \\
\hline Oxytocin & Yes & $3(2.8)$ & $21(19.6)$ & $<0.001$ & $0.14(0.04,0.46)$ \\
augmentation & No & $104(97.2)$ & $86(80.4)$ & & \\
\hline Emergency C/S & Yes & $7(6.5)$ & $5(4.7)$ & 0.77 & $1.4(0.46,4.27)$ \\
& No & $100(93.5)$ & $102(95.3)$ & & \\
\hline $1^{\text {st }}$ minute Apgar & $<7$ & $13(12.1)$ & $17(15.9)$ & 0.43 & $0.76(0.39,1.50)$ \\
& $\geq 7$ & $94(87.9)$ & $90(84.1)$ & & \\
\hline $5^{\text {th }}$ minute Apgar & $<7$ & $1(0.9)$ & $3(2.8)$ & 0.62 & $0.33(.04,3.15)$ \\
& $\geq 7$ & $106(99.1)$ & $104(97.2)$ & & \\
\hline NBSCU admission & Yes & $11(10.3)$ & $9(8.4)$ & 0.64 & $1.22(0.53,2.83)$ \\
& No & $96(89.7)$ & $98(91.6)$ & & \\
\hline
\end{tabular}

\section{Discussion}

The provision of effective obstetric services for the management of common obstetric conditions is a necessary means of reducing maternal morbidity and mortality especially in developing countries. As demonstrat- ed in this study, early amniotomy may be included into the list of such effective practices which may explain why it was introduced as an element of active manage- ment of labour ${ }^{15}$. The observed reduction in the dura- tion of labour in the amniotomy group of this study has been attributed to the increased efficiency of uterine contraction and prevention of labour dysfunction ${ }^{4,16}$. Therefore, early amniotomy may be considered as a low-cost accessible intervention to reduce prolonged labour and its associated complications - this observation has practical implication in low resourced settings including Nigeria, characterized by high maternal/perinatal morbidity and mortality. The significant shorter duration of labour associated with amniotomy in this study is similar to the findings of the only identifiable related study from Nigeria ${ }^{13}$. While we encourage more studies in the subject from other populations of the country, the available evidence suggests that this simple intervention (early amniotomy) may be effective in the wider Nigerian population when utilized appropriately. Furthermore, the observed shorter duration of labour associated with amniotomy in our study, is similar to the reports of related studies outside Nigeria ${ }^{12,14,17,18}$. However, it contrasts the reports of other related studies that showed no significant association between amniotomy and the duration of labour ${ }^{4,19}$. A recent systematic review of 15 studies involving 5583 women had noted 
no clear association between amniotomy and duration of labour which holds for both primiparous and multiparous sub-groups; however, the observed high heterogeneity among the included trials might have impacted on the outcome of the review ${ }^{4}$.

This study also demonstrated less need for oxytocin use when amniotomy was done when compared with the non-amniotomy group, which is in line with the report of a related study ${ }^{12}$. This finding may not be surprising considering the suggested effect of amniotomy on the efficiency of uterine contraction discussed earlier. In fact, according to this study, sixteen women needed to receive early amniotomy in labour in order to prevent one case of oxytocin augmentation. Though this number needed to treat (NNT) does not appear very low, it may have positive practical impact in resource poor settings prevalent in developing countries. For instance, the reduction in oxytocin requirement implies that the extra financial cost of procuring oxytocin as well as the intense pain resulting from oxytocin use in labour can be reduced by early amniotomy of eligible women. This possible cost reduction effect of early amniotomy is most important in our setting where payment for maternal and neonatal health care services is usually out of pocket because of lack of functional community health insurance system. Unfortunately, our study did not cover these outcomes therefore; we suggest that future studies in this subject in under-resourced settings should consider including indicators on cost assessment, client's pain perception and satisfaction.

It is noteworthy that the study population used for this study was essentially low risk pregnant women so, it is probable that the effect of early amniotomy in this group may differ for high risk pregnant sub-group.

Like the study from South-western Nigeria ${ }^{13}$, the incidence of emergency caesarean section in our study has no association with early amniotomy in labour. This finding is unfortunate for our environment where aversion for caesarean section exists ${ }^{20-22}$. Though, these studies' findings are consistent with the result of a recent systematic review ${ }^{4}$, the effect of small sample size cannot be ruled out because caesarean section rate was a secondary measure in the studies; so, there is a need for a large sample multicenter collaborative study to clarify their findings especially the secondary measures. Lastly, the neonatal outcome in terms of the low Apgar scores, and need for NBSCU admission had no rela- tionship with early amniotomy in labour which suggests that the procedure does not add to the complications of normal labour. This observation was noted in related studies ${ }^{13,17}$. No case of umbilical cord prolapse was observed in this study despite the possible causal relationship it appears to have with amniotomy ${ }^{2}$ - this finding may also support the safety of the early amniotomy in uncomplicated labour.

Outside the limitation of small sample size and restriction of the study to low risk pregnant women discussed earlier, the study could only measure randomization to delivery interval because of the difficulty in determining the actual time at which a labouring woman reached full cervical dilatation. Furthermore, contamination was inevitable for the few participants in the control group that had amniotomy at cervical dilation of less than 6 $\mathrm{cm}$ due to slow progress of labour however; the effect on the primary outcome was likely to be very minimal.

\section{Conclusion}

Early amniotomy when compared to fetal membrane conservation reduced the duration of labour and the need for oxytocin augmentation among term singleton pregnant women in Enugu, Nigeria. It also has no negative effect on caesarean section rate and neonatal outcomes. Therefore, its routine use in the management of uncomplicated labour may reduce prolonged labour and its attendant effects on maternal and neonatal health.

\section{Acknowledgment}

Authors acknowledge our research assistants, midwifery and other staff of antenatal clinic and labour ward of the UNTH, Enugu, Nigeria.

\section{Conflict of interest}

The authors declare no conflicts of interest.

\section{References}

1. Orhue AAE (2005) Normal labour. In: Agboola A (ed) Textbook of Obstetrics \& Gynaecology for Medical Students, 2nd edn. Heinemann Educational Books PLC, Ibadan, pp 283-302

2. Cohain JS (2013) The less studied effects of Amniotomy J Matern Fetal Neonatal Med 26:1687-1690

3. World Health Organization (WHO) (2000) Managing complication in pregnancy and childbirth: A guideline for midwives and doctors WHO, Geneva

4. Smyth RM, Markham C, Dowswell T (2013). Amniotomy for shortening spontaneous labour. Cochrane Database Syst Rev 6: CD006167 
5. Rogers R, Gilson GJ, Miller AC, Izquierdo LE, Curret LB, Qualls CR (1997). Active management in labour. Does it make a difference? Am J Obstet Gynecol 177:599-

605

6. Archie CL, Roman AS (2013) Normal \& Abnormal Labor \& Delivery. In: Decherney AH, Nathan L, Laufer $\mathrm{N}$, Roman AS (eds) Current Diagnosis \& Treatment in Obstetrics \& Gynecology 11th edn McGraw-Hill Companies, New York, pp $154-162$

7. ACOG Practice Bulletin No. 107 (2009) Induction of labor. ACOG Committee on Practice Bulletins -- Obstetrics Obstet Gynecol 114: 386-397

8. Goffinet F, Fraser W, Marcoux S, Breart G, Moutquin JM, Daris M (1997) Early amniotomy increases the frequency of fetal heart rate abnormalities. $\mathrm{BrJ}$ Obstet Gynaecol 104:548-553.

9. Busowski JD, Parsons MT (1995) Amniotomy to induce labour. Clin Obstet Gynecol38: 246-58.

10. Federal Ministry of Health (FMOH) Nigeria (2010) National Guidelines for Prevention of Mother-ToChild Transmission of HIV (PMTCT) FMOH Abuja 11. Baskett TF, Calder AA, Arulkumaran S (2007) Mun- ro Kerr's Operative Obstetrics. 11th edn Elsevier Ltd, Edinburgh

12. Fraser WD, Marcoux S, Moutquin JM, Christen A (1993) Effect of early amniotomy on the risk of dystocia in nulliparous women. The Canadian Early Amniotomy Study Group. N Engl J Med 328: 1145- 1149

13. Ajadi MA, Kuti O, Orji E,O. Ogunniyi SO, Sule SS (2006) The effect of amniotomy on the outcome of the spontaneous labour in uncomplicated pregnancy. $J$ Obstet Gynaecol 26: 631-634
14. Johnson N, Lilford R, Guthrie K, Thornton J, Barker M, Kelly M (1997) Randomized trial comparing a policy of early amniotomy with selective amniotomy in uncomplicated labour at term. BrJ Obstet Gynaecol 104:340-346

15. O'Driscoll K, Foley M, MacDonald D (1984) Active management of labor as an alternative to cesarean section for dystocia. Obstet Gynecol 63: 485-490

16. Busowski JD, Parsons MT (1995) Amniotomy to induce labor. Clin Obstet Gynecol 38: 246-258

17. UK Amniotomy Group (1994) A multicentre randomized trial of amniotomy in spontaneous first labour at term. Br J Obstet Gynecol 101:307-309

18. Barrett JF, Savage J, Philips K, Lifford RJ (1992) Randomised trial of amniotomy in labour versus the intention to leave membranes intact until second stage. Br J Obstet Gynaecol 99: 5-9

19. Fraser WD, Sauve R, Parboosingh IJ, Fung T, Sokol R, Persaud D (1991) A randomized controlled trial of early amniotomy. BrJ Obstet Gynaecol98: 84-91

20. Okonkwo NS, Ojengbede OA, Morhason_Bello IO, Adedokun BO (2012) Maternal demand for cesarean section: perception and willingness to request by Nigerian antenatal clients. Int J Womens Health 4: 141-8

21. Sunday_Adeoye I, Kalu C (2011) Pregnant Nigerian women's view of cesarean section. NigerJ Clin Pract 14: 276-9

22. Nkwo PO, Onah HE (2009) Does a preference for symphysiotomy over caesarean section reduce the operative delivery rate? Trop Doct 39: 198-200 